\title{
Climate effects on the growth of Pinus latteri and Pinus kesiya at the Intakin Silvicultural Research Station, Chiang Mai Province, Thailand
}

\author{
MATAYAWEE NAUMTHONG, KRITSADAPAN PALAKIT, KHWANCHAI DUANGSATHAPORN, \\ PATSI PRASOMSIN, PICHIT LUMYAI ${ }^{\vee}$ \\ Department of Forest Management, Faculty of Forestry, Kasetsart University. 50 Ngamwongwan Rd., Lat Yao, Chatuchak, Bangkok 10900, Thailand \\ Tel./fax.: +66-8505-60643, `email: fforpcl@ku.ac.th
}

Manuscript received: 24 March 2021. Revision accepted: 11 April 2021.

\begin{abstract}
Naumthong M, Palakit K, Duangsathaporn K, Prasomsin P, Lumyai P. 2021. Climate effects on the growth of Pinus latteri and Pinus kesiya at the Intakin Silvicultural Research Station, Chiang Mai Province, Thailand. Biodiversitas 22: $2512-2519$. Relationship between the growth of two pine species, Pinus latteri and Pinus kesiya, and past climatic factors are studied. Standard dendrochronological techniques were used on 40 core samples obtained from 20 trees from each species to cross-date tree-ring width and determine the growth patterns of each species. Over a period spanning from 1980-2019 (P. latteri) and 1984-2019 (P. kesiya), the calculated mean ring-width values were 0.596 and $0.430 \mathrm{~cm}$ per year, respectively. An analysis of the relationship between tree-ring width of $P$. latteri and climatic data indicated a positive correlation with the relative humidity in April. However, a negative correlation was observed with the temperature in April and August. The factors limiting the growth of $P$. latteri the most were the temperature in August $\left(\mathrm{r}^{2}=0.228 ; \mathrm{P}<0.01\right)$. The index constructed for $P$. kesiya indicated a positive correlation with extreme minimum relative humidity in December and extreme maximum temperature in March. The factors limiting the growth of $P$. kesiya with a significant correlation, were the relative humidity in April $\left(\mathrm{r}^{2}=0.173\right)$ and temperature in May $\left(\mathrm{r}^{2}=0.184\right)$. These results can be used to plan the management of forest plantations and to select suitable areas for the cultivation of pine trees in Thailand.
\end{abstract}

Keywords: Climate growth response, limiting factor, Pearson correlation coefficient, tree-ring width index, tree ring chronology

\section{INTRODUCTION}

Climate change is a very important environmental issue around the world, with an even more relevance on regional scales in specific zones, mainly resulting from various anthropogenic activities. According to the World Metrological Organization report filed in the United Kingdom, it was found that the average global temperatures during 2018 increased by $1.42{ }^{\circ} \mathrm{F}$ around the world relative to the $20^{\text {th }}$ century (NOAA 2019). These effects of climate change can have several impacts on both human and natural resources, especially forest resources, which is an important resource that benefits human beings both directly and indirectly. Studying the past climate could provide some evidence as to the conditions during those times, for which scientists use proxy data to reconstruct and study the climate in the past. Through the techniques of dendrochronology, tree rings can be used to determine the relationship with climate data such as rainfall and temperature. The effects of climate can yield different results depending on the study site and species from which the tree-rings have been derived (Palakit et al. 2015a, 2015b, 2018, 2019; Susatya and Yansen 2016).

Extensive dendrochronological studies have been conducted in Thailand and include species like Pinus latteri Mason. The species has been used to determine the response to rainfall throughout the year at Thung Salaeng Luang, Phitsanulok province and P. kesiya Royle ex Gordon presented positive response with rainfall and negative with November temperature at the Nam Nao site, Phechabun Province (Buckley et al. 1995), as these species respond readily to the changes in climatic factors in Thailand. P. latteri and P. kesiya are found extensively in the northern and northwestern regions of Thailand. It has been reported that pine trees, found in various parts of Thailand, respond to climate variability in terms of rainfall in May during the beginning of the rainy season and to variations in temperature during the transition from dry to wet season in April to May (Pumijumnong and Wanyaphet 2006; Pumijumnong and Eckstein 2011). Other previous studies have reported on the effect of climate changes on the growth ring width in teak and pine (Buckley et al. 2007; Pumijumnong 2012; Duangsathaporn and Palakit 2013; Palakit et al 2015b, 2019; Buajan et al. 2016; Muangsong et al. 2016, 2018; Sangram et al. 2016; Auykim et al. 2017; Lumyai and Duangsathaporn 2017a, 2017b; Preechamart et al. 2018; Khantawan et al. 2019; Buareal et al. 2020; Lumyai et al. 2020; Pumijumnong and Palakit 2020; Rakthai et al 2020).

The two native pine species in Thailand, $P$. latteri and $P$. kesiya, have been used to study the changes in growth as a result of climate variability using dendrochronology. These studies compared the species sampled from various natural forests, and have reported the differences in growth based on landscape )Buckley et al 1995; Pumijumnong and Wanyaphet 2006; Pumijumnong and Eckstein 2011(. At present, the natural forests are unable to fulfill the demand and quality of the timber supplied to the timber industry 
because the natural forests are difficult to manage, has a long interval between tree felling cycle and is economically not feasible. Forestry statistics calculated for the 5 year period of 2009-2014, however, indicate that Thailand imported pine timber and lumber worth 1523 million Baht/year. Even though there is a great potential for pine plantations in Thailand, with additional economic and environmental benefits, the area under pine plantations is very limited. Forest plantations can help to meet such demands, resulting in economic benefits to the plantation owners.

The objective of this study was to determine the relationship between climatic factors which can affect the development of tree-ring width in forest plantations of $P$. latteri and $P$. kesiya growing at the Intakin Silvicultural Research Station located in Chiang Mai Province, Thailand.

\section{MATERIALS AND METHODS}

\section{Study site}

The study site at the Intakin Silvicultural Research Station, Chiang Mai Province, is located on a 45-kilometer stretch next to the Chiang Mai-Fang road, Highway 107, Inthakin Subdistrict, Mae Taeng District, Chiang Mai Province. The station is located at a latitude of $19^{\circ} 09^{\prime}$
02 ' $\mathrm{N}$ and longitude of $98^{\circ} 56^{\prime}$ 5' $^{\prime} \mathrm{E}$, at an altitude of 400 meters above sea level. The climate data were obtained from the Thai Meteorological Department, located in the Chiang Mai Province $\left(18^{\circ} 46^{\prime} 17^{\prime} ' \mathrm{~N}\right.$ and longitude of $98^{\circ} 58^{\prime} 21^{\prime \prime} \mathrm{E}$ ), which is at a distance of around 47 kilometers from the study area. The average temperature around the site is $26^{\circ} \mathrm{C}$ with the maximum temperature reaching around $32{ }^{\circ} \mathrm{C}$, while the average minimum temperature fluctuates around $20.9^{\circ} \mathrm{C}$. The area receives an average annual rainfall of $1,136 \mathrm{~mm}$, with an average relative humidity of around $70 \%$. The forest is broadly classified as a deciduous forest. The study site covers an area of approximately 1,392 rai (222.72 ha), which is an area of $P$. latteri 12 rai (1.92 ha), planted in 1978 and an area of $P$. kesiya 125 rai (20 ha), planted in 1981. (Figure 1). The local climate data for the period of 1980 to 2019 included the total monthly rainfall, mean monthly relative humidity (RHmean), mean maximum monthly relative humidity (RHMmax), mean minimum monthly relative humidity (RHMmin), extreme minimum monthly relative humidity (RHEmin), mean monthly temperature (Tmean), mean maximum monthly temperature (TMmax), mean minimum monthly temperature (TMmin), extreme maximum monthly temperature (TEmax), and extreme minimum monthly temperature (Temin) (Figure 2).

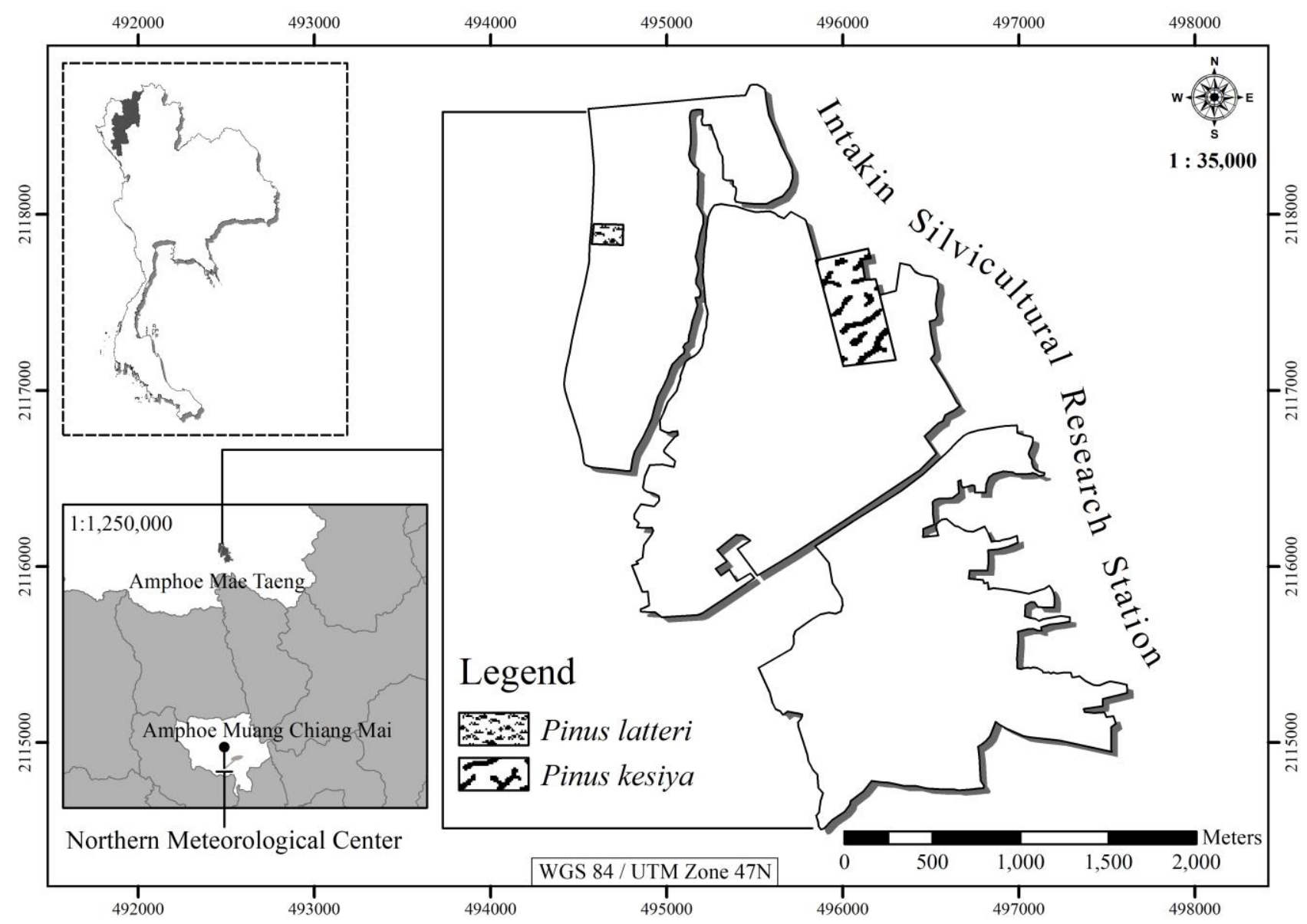

Figure 1. Map showing the study site of Pinus latteri and P. kesiya plantation at the Intakin Silvicultural Research Station in Chiang Mai Province, Thailand 


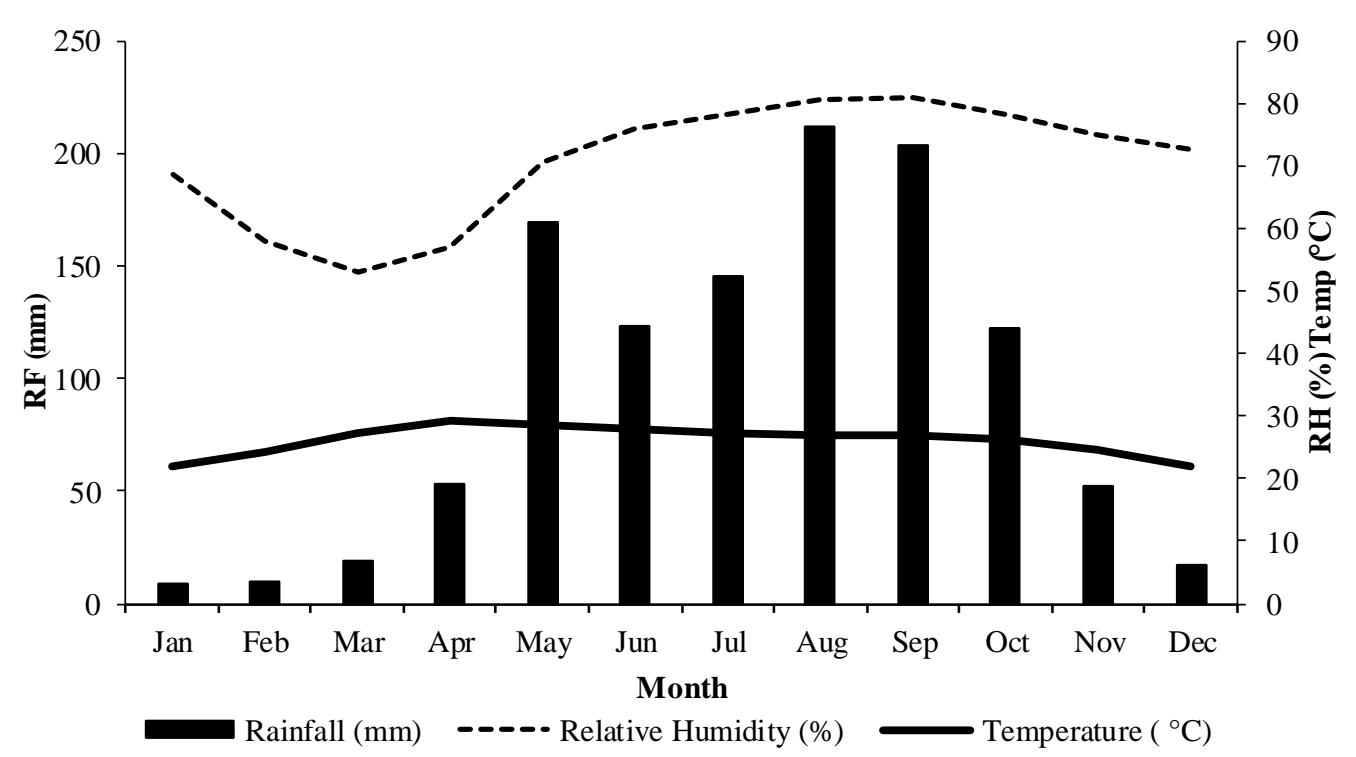

Figure 2. The local climate data, including total monthly rainfall, mean monthly relative humidity, mean monthly temperature, as published by the Thai Meteorological Department

\section{Fieldwork sample collection}

The cores samples of $P$. latteri and $P$. kesiya, growing in the plantation, were taken during June 2020, with a total of 40 cores sampled from 20 living trees of each species. Two core samples from each tree were taken using an increment borer at a breast height of 1.30 meter in the opposite directions of the stem. The core samples were selected based on the criteria of dominance, crown symmetry, and location in a well-drained area. Additionally, it was ensured that the selected tree did not have any obvious bruises, scars, unusual characteristics, and other issues, for instance, disease, insect disturbance, and fire damage. At the Laboratory of Tropical Dendrochronology, Faculty of Forestry, Kasetsart University, Bangkok, Thailand, the sample cores were prepared according to standard dendrochronological techniques (Stokes and Smiley 1968). All the samples were dried at room temperature, glued and mounted onto wooden supports with the cross-sectional position pointing upward. The samples were scrubbed with sandpapers number 120, 220, 300, and 400 until the tree-ring surface was visible enough under a microscope.

\section{Ring width measurement and construction of tree-ring index}

The tree-ring widths were compared for their growth patterns within a tree and between trees to classify the annual rings, false rings, or missing rings, using crossmatching techniques. Subsequently, the tree-ring widths were used to construct a time series for each year with cross-dating techniques (Ferguson 1970; Fritts 1976). The samples made using cross-matching and cross-dating were observed using a $4 \times-40 \times$ stereo microscope. The Velmex measuring system was used to measure the tree-ring width at a resolution of $0.01 \mathrm{~mm}$ and the results were displayed on a computer through the $\mathrm{J} 2 \mathrm{X}$ program (Voor Tech Consulting 2008). The accuracy of tree-ring growth and a given calendar year was verified using the COFECHA program (Holmes 1983). The sample cores passed the significance test at a $99 \%$ confidence level and a Pearson correlation coefficient of 0.5155 . The tree-ring width was analyzed using appropriate statistics indicating the relevant properties, such as correlation with master, standard deviation, autocorrelation, and mean sensitivity (Fritts 1976). Later, the tree-ring width index was standardized to remove any growth or age trends using the ARSRTAN program and autoregressive modeling (Cook and Kairiukstis 1990). The detrending of analyzed tree-ring width index was done using a negative exponential curve or a straight line with a negative slope by dividing the actual value from the predicted value and dividing the new value by the average and was labeled as the master chronology or tree ring index. The reliability of acceptable cores samples using the expressed population signal (EPS) was $\geqq 0.85$ (Wigley et al. 1984). Finally, a running RBar, which measures the correlation between ring-width series through time, was also calculated (Cook and Kairiukstis 1990).

\section{Climate-growth response analysis and limiting factors}

The correlation of ring widths of $P$. latteri and $P$. kesiya with the climate data was determined, the ring-width data being the dependent variable and the climatic data as the independent variables. Statistical measures were determined which included simple correlation, multiple regression, stepwise regression as indicated by the Pearson's correlation coefficient ( $\mathrm{r}$ ), and the coefficient of determination $\left(\mathrm{r}^{2}\right)$. 


\section{RESULTS AND DISCUSSION}

\section{Tree-ring chronology statistics}

A total of 40 samples from 20 P. latteri trees passed the cross-matching, were cross-dated, and the accuracy of time series values was determined with the COFECHA Program (Holmes 1983). The crossed ring width data could be extended back by up to 40 years, covering a period from 1980 to 2019. These sample cores passed the significance test at a $99 \%$ confidence level and had a Pearson correlation coefficient of 0.5155 . The mean series intercorrelation was 0.586 , the standard deviation was 0.416 , the average mean sensitivity was 0.306 , and the mean length of the series was 35 years. The mean ring-width value was $0.596 \mathrm{~cm}$ per year (Figure 3A). The tree-ring width index covered a period from years 1982 to 2019 (Figure 3C).

A total of 40 samples from $20 P$. kesiya trees were successfully cross-dated. The tree-ring widths passed the significance test at a $99 \%$ confidence level with a Pearson correlation coefficient of 0.5155 . The crossed ring width data could be extended back by up to 36 years, covering a period from 1984 to 2019. The mean series intercorrelation was 0.698 , the standard deviation was 0.449 , the average mean sensitivity was 0.364 , and the mean length of series was 34.8 years (Figure $3 \mathrm{~A}$ ). The mean ringwidth value was $0.430 \mathrm{~cm}$ per year. The tree-ring index of $P$. kesiya covered a period from years 1984 to 2019 (Figure 3D).

We quantitatively evaluated the chronology signal strength by using the expressed population signal or EPS (Wigley et al. 1984). The EPS for the constructed index of P. latteri (Figure 3D) during the period from 2000 to 2019 and $P$. kesiya during 1989 to 2019 was 0.85 greater than the standard value, and was accepted as being reliable. The running Rbar (Cook and Kairiukstis 1990), or the autocorrelation of the tree-ring index with time, was determined for many samples during 2005 - 2009 for $P$. latteri and similarly for several $P$. kesiya samples during 1989 - 1999 (Figure 3E). Overall, indices of both types of pine in the study area indicated sufficient replication.

P. latteri grew rapidly between $1990-2002$ and after that, the growth declined until the year 2019. P. kesiya experienced faster growth during $1984-1991$ relative to that of $P$. latteri and after that, the growth was noticeably lower. When P. latteri and P. kesiya of the same age were compared at during the years between $1984-1990, P$. kesiya had better growth than P. latteri, but during 1991 2004 it was observed that $P$. latteri grew at a faster rate than $P$. kesiya until the period from $2005-2019$, when the growth of $P$. latteri and $P$. kesiya declined at a similar rate.

The mean ring-width values of $P$. latteri were higher than $P$. kesiya. It can be concluded that at first, the growth of $P$. latteri was high and then gradually decreased, while the growth of $P$. kesiya was comparatively slower. The growth rates of the two pine species in this plantation can be considered as being relatively high compared to that reported by Chaudhary and Bhattacharyya (2002). $P$. kesiya growing on the Shillong plateau in northeast India had an average growth of ring-widths between $0.16-0.24$ $\mathrm{cm}$ per year. Missanjo E. (2016) indicated that the average growth of $P$. kesiya ring in Malawi was around $0.42 \mathrm{~cm}$ per year. Pumijumnong and Eskstein (2011) studied P. latteri and $P$. kesiya growing in a natural forest in northwestern Thailand and found that these pines have a mean growth of ring-widths approximately between $0.2-0.4 \mathrm{~cm}$ per year. Lumyai and Duangsathaporn (2017) reported that the $P$. latteri, growing in the Phutoei National Park in Suphan Buri province, central Thailand, had a mean ring-width growth of 0.86-1.63 cm per year. Yordtong et al. (2019) studied the P. latteri at the Phu Kradueng National Park, Loei Province, Thailand and estimated a mean ring-width growth of $0.358 \mathrm{~cm}$ per year. Lumyai et al. (2020) studied $P$. latteri and reported a mean ring-width of $.113 \mathrm{~cm}$ per year at a study site in Chiang Mai province, Thailand. The study found that $P$. latteri and $P$. kesiya in the plantation had a higher growth compared to pine growing in natural forests and also reported a higher growth rate for $P$. latteri relative to $P$. kesiya. Therefore, it can be concluded that $P$. latteri should be promoted in forest plantations around Thailand.

\section{Climate-growth response and limiting factors}

The relationship between growth of $P$. latteri as estimated by its tree-ring index with the climate data was analyzed. We found a significant positive correlation $(\mathrm{P}<0.05)$ with the relative humidity in April $(\mathrm{r}=0.357)$ and a significant negative correlation $(\mathrm{P}<0.05)$ with Tmean in April and August ( $\mathrm{r}=-0.345$ and -0.365 , respectively). Rainfall, RHMmax, RHMmin, RHEmin, TMmax, TMmin, TEmax, and Temin did not have a significant correlation with the tree-ring index. The relationship with TMmax during the October of previous year was found to have a significant negative correlation $(\mathrm{r}=-0.418 ; \mathrm{P}<0.05)$ and a significant positive correlation $(\mathrm{P}<0.05)$ was observed with TMmin in April $(r=0.369)$ of the previous year (Figure 4A, 4B). Factors limiting the growth of tree-ring index of $P$. latteri were analyzed with multiple regression. It was found that the temperature in August influenced the growth with a significant correlation $\left(\mathrm{r}^{2}=0.228 ; \mathrm{P}<0.01\right)$ and can be written mathematically as in Eq.1:

$\operatorname{Index}_{P L}=4.713-0.138($ Tmean $) ; \mathrm{r}^{2}=0.228, \ldots \ldots \ldots \ldots$ (eq. 1$)$

Where; Index $P L$ is the tree-ring index of $P$. latteri estimated by using the temperature in August and Tmean is the mean temperature for each year corresponding to the tree-ring index. 

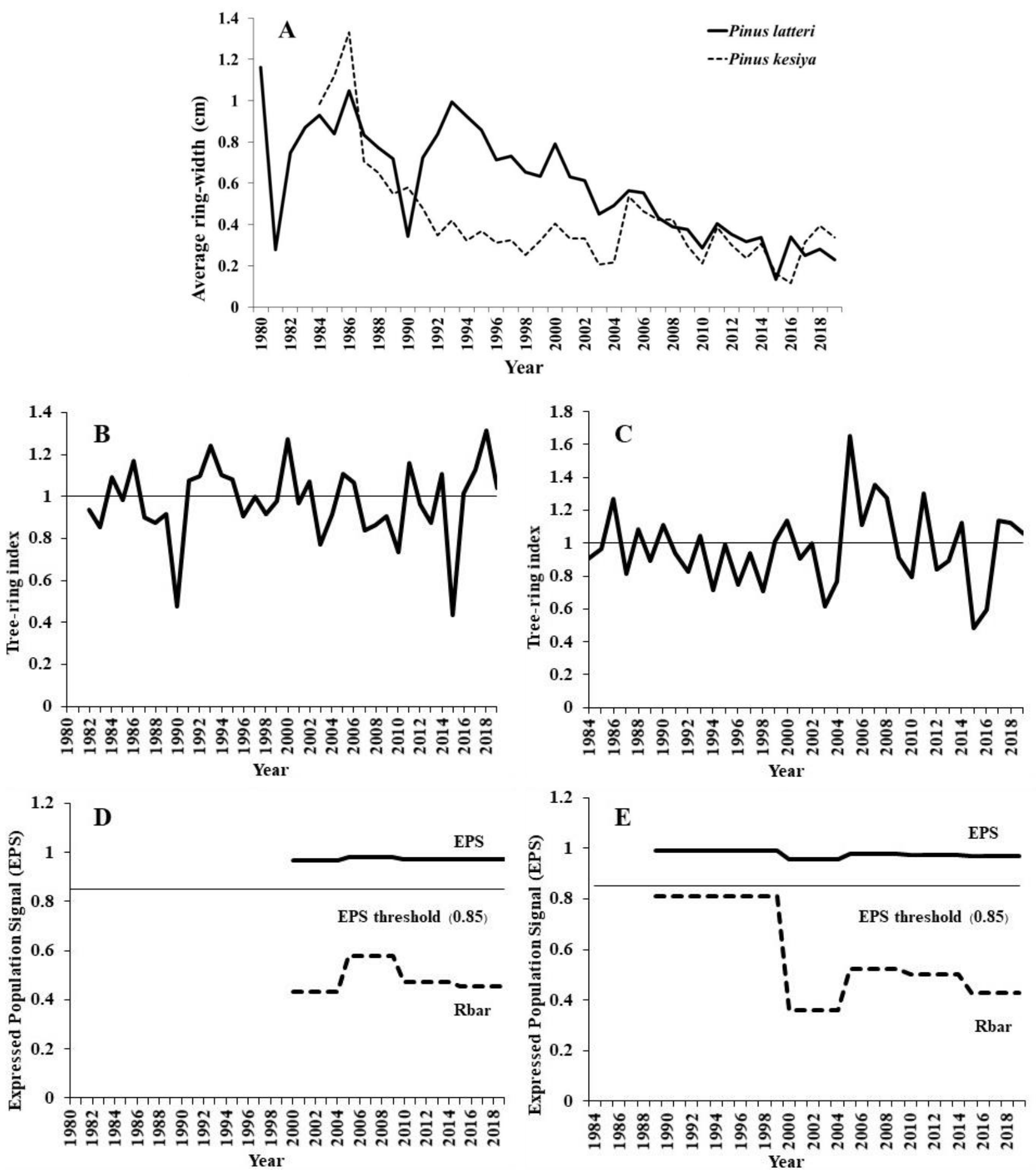

Figure 3. A. Mean ring-widths of Pinus latteri (solid line) and P. kesiya (dashed line). B. Standardized chronological index of $P$. latteri and C. P. kesiya, respectively. Running EPS (solid line) and Rbar (dashed line) values for the reconstructed ring indices of: D. P. latteri and E. P. kesiya. 

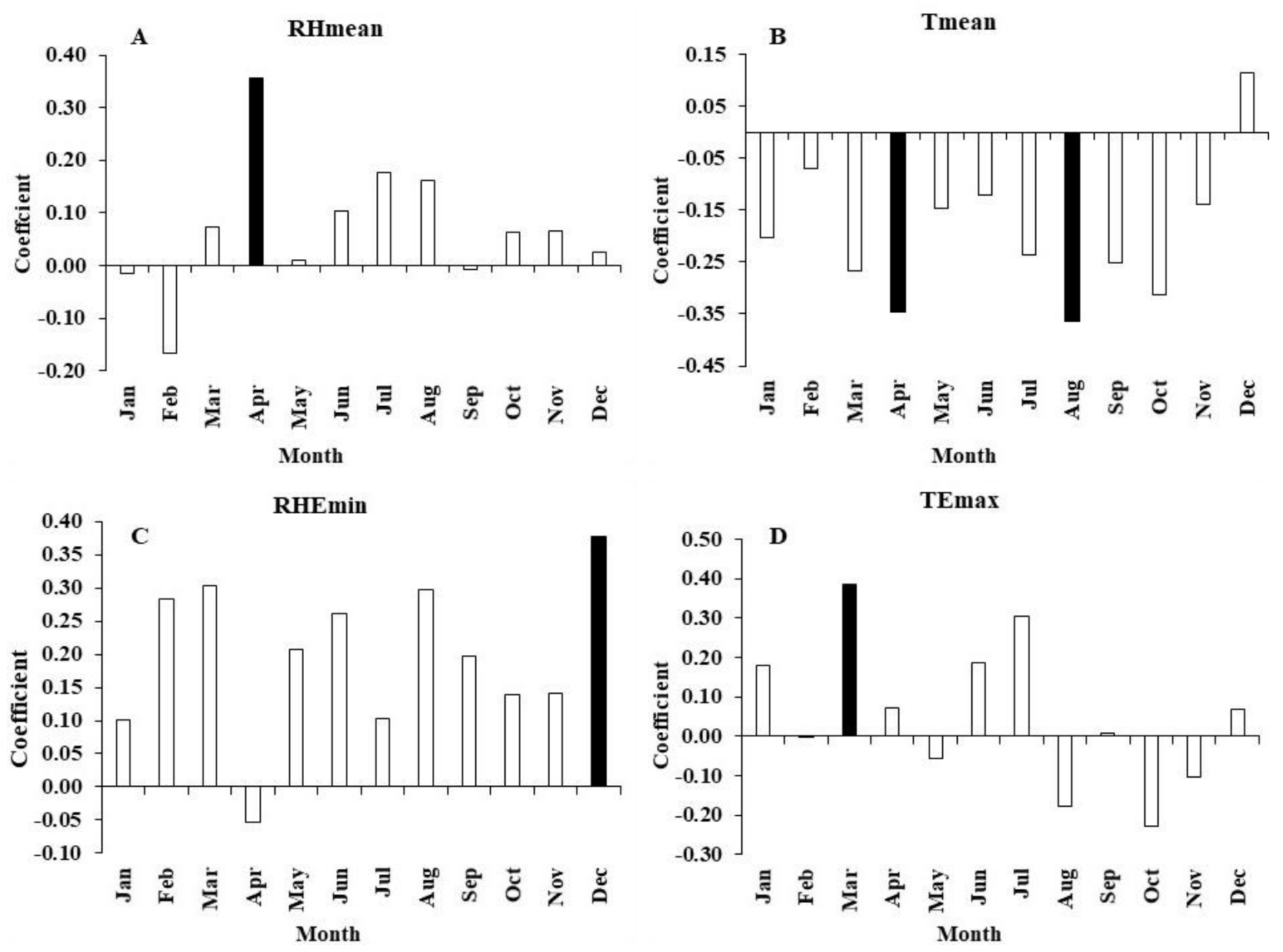

Figure 4. A. and B. correlation coefficient between the climatic data (RHmean and Tmean) and the growth of $P$. latteri tree-ring width. C. and D. correlation coefficient between the climatic data (RHEmin and TEmax) and growth of $P$. kesiya tree-ring width. The black bars indicate a significant correlation.

We found a significant positive correlation $(\mathrm{P}<0.05)$ with RHEmin in December $(r=0.377)$, and a significant positive correlation $(\mathrm{P}<0.05)$ with TEmax in March $(\mathrm{r}=$ 0.385 ) with the growth of tree-ring index of $P$. kesiya. The other climate variables, including rainfall, RHmean, RHMmax, RHMmin, Tmean, TMmax, TMmin, and TEmin did not have a significant correlation with the tree-ring growth, while a significant positive correlation $(\mathrm{P}<0.05)$ was found with Tmean in March and April $(r=0.357$ and 0.368 , respectively) of the previous year. TMmax in January $(r=0.383)$ and TEmax in March of the previous year $(r=0.427)$ had a significant positive correlation $(\mathrm{P}<0.05)$, while a significant negative correlation $(\mathrm{P}<0.05)$ was observed with TEmax in June $(r=-0.367)$ of the previous year (Figure 4C, 4D). The relative humidity in April $\left(\mathrm{r}^{2}=0.173\right)$ and Tmean in May $\left(\mathrm{r}^{2}=0.184\right)$ influenced the growth of $P$. kesiya, with a significant correlation $(\mathrm{P}<0.05)$, as indicated by Eq. 2 .

Index $_{P K}=3.466-0.088$ (Tmean); $\mathrm{r}^{2}=0.184$,

Where; Index $P_{P K}$ is the tree-ring index of $P$. kesiya estimated using the temperature in May and Tmean is the mean temperature for each year corresponding to the treering index.
A growth comparison was made between $P$. latteri and $P$. kesiya in the Intakin Silvicultural Research Station, which is a forest plantation managed according to silvicultural practices. We found that $P$. latteri had a better growth compared to $P$. kesiya, as indicated by a mean ringwidth of $0.166 \mathrm{~cm}$ per year. Due to the appropriate elevation for growing. Usually, P. latteri grow well at an altitude of 300-700 meters above sea level )Northern Silvicultural Research Center 2019). The results of the present study found that Tmean in August of each year (middle of the rainy season) had a significant correlation $(\mathrm{P}<0.01)$ with the tree-ring index of $P$. latteri. This was found to be the month receiving the highest rainfall with a high relative humidity. As a result, the temperature in August dropped and affected the growth of $P$. latteri. Therefore, the factor limiting the growth of $P$. latteri was Tmean. Tmean in May of each year (period spanning the dry season and the beginning of the rainy season) was significantly correlated $(\mathrm{P}<0.05)$ with the ring growth and was the limiting factor for $P$. kesiya, resulting in increased rainfall and higher relative humidity, lowering the temperature as well as growth response of $P$. kesiya. We conclude that the $P$. kesiya growth was lower than $P$. latteri. Therefore, P. kesiya should be planted in open 
forest areas, in order to vegetate the area and after becoming a pioneer species that can rapidly grow and be used to reclaim the area. $P$. latteri should be promoted in a forest plantation to increase the economic value of the forest for trade and export to various countries.

Climate variability affected the growth of $P$. latteri and $P$. kesiya in Thailand differently. The results of the present study are consistent with the results from several previous studies reporting that $P$. latteri can grow well in the postmonsoon (November to February) period, and is its optimal growing season. We found that the Tmean in August is an important factor in the growth of $P$. latteri. The highest rainfall in August and the mean relative humidity in September induce $P$. latteri growth similar to a previous study conducted in Thailand by Yordtong et al. (2019), who found a significant positive correlation $(\mathrm{P}<0.05)$ between the growth response of $P$. latteri with the TMmin in October and RHmean in March, October, and November were the main limiting factors for P. latteri. An increase in the TMmin at the end of the year, in addition to an increase in the RHmean at the end of the year to the beginning of the next year, would increase the growth rate of $P$. latteri. In contrast, the temperatures tend to drop from May to January.

The temperatures declined in the rainy season induce $P$. latteri growth as similar as the study of Lumyai et al. (2020) who studied the influence of climate on the growth of $P$. latteri in the northern region of Chiang Mai, Thailand. The result found a significant negative correlation $(\mathrm{P}<0.01)$ with the mean temperature in August was reported and the temperature in September was the limiting factor affecting the growth of $P$. latteri. Lumyai and Duangsathaporn (2017a) studied the relationships between tree growth and climatic data in Pinus merkusii in Central Thailand and found that the chronology had a high positive correlation $(\mathrm{P}<0.01)$ with the temperature of current year in October Which was found to have a temperature of $27.75{ }^{\circ} \mathrm{C}$. This was the period when the temperature dropped until the growth of $P$. latteri increased again. This showed that an optimum temperature drop can result in a better growth of $P$. latteri. This is also consistent with the research of Rakthai et al. (2020), who studied the growth of $P$. latteri at three sites in Northeastern Thailand and found that the growth of $P$. latteri had a significant negative correlation $(\mathrm{P}<0.05)$ with the temperature (mean, maximum and minimum) from April to August. Buckley et al. (2007) analyzed the growth of rings in $P$. latteri growing in Lao P.D.R. and found a significant positive correlation $(\mathrm{P}<0.05)$ with the maximum temperature in August to September, which was the main limiting factor controlling the growth of $P$. latteri.

On the other hand, the growth in P. kesiya was found to be most affected by the relative humidity in April and the temperature in May, which is a period spanning the dry and rainy season It was found that the increase in relative humidity and lowering of temperature during the early rainy season resulted in an increase in growth rate of $P$. kesiya. This was found to be consistent with the research of
Pumijumnong and Eckstein (2011), who studied the treering widths of $P$. latteri and $P$. kesiya and found that their growth was negatively correlated $(\mathrm{P}<0.05)$ with the mean temperature during the pre-monsoon period from March to May. As such, the change from the dry season to the rainy season was the period that affects the growth of $P$. latteri and P. kesiya. Pumijumnong and Wanyaphet (2006) studied the seasonal cambial activity and tree-ring formation in P. latteri and P. kesiya and found that the growth in both the species had a positive correlation with the mean temperature during November to July and a negative correlation with mean temperature during March to October. Chaudhary and Bhattacharyya (2002) studied the tree rings of $P$. kesiya in Shillong, India and found a positive and significant correlation with the temperature and rainfall in during March. From the present study, our findings are consistent with the previous studies which conclude that $P$. kesiya can grow well during the premonsoon period (May to October). Pumijumnong et al (2021) studied climate control of cambial dynamics and tree-ring in $P$. latteri and $P$. kesiya and found that the growth in both the species had a positive correlation with the relative humidity in April and May. This study found temperature is the important factor in tree-ring width of native pines in Thailand as similar as the study of Wang et al. (2017) who studied Korean pines growing and reported that temperature is the key limiting factor in controlling the growth of Korean pine

In summary, mean ring-width values of $P$. latteri and $P$. kesiya were 0.596 and $0.430 \mathrm{~cm}$ per year, respectively. A total of 40 samples from 20 Pinus latteri Mason trees passed cross-dated. The crossed ring width data could be extended back by up to 40 years, covering a period from 1980 to 2019 . The mean series inter-correlation was 0.586 , the standard deviation was 0.416 , the average mean sensitivity was 0.306 , and the mean length of the series was 35 years. A total of 40 samples from 20 Pinus kesiya trees were successfully cross-dated. The crossed ring width data could be extended back by up to 36 years, covering a period from 1984 to 2019 . The mean series intercorrelation was 0.698 , the standard deviation was 0.449 , the average mean sensitivity was 0.364 , and the mean length of series was 34.8 years. The factors limiting the growth of $P$. latteri the most were the temperature in August. The factors limiting the growth of $P$. kesiya were the relative humidity in April and temperature in May, that temperature is the key limiting factor in controlling the growth of pine in Thailand, this information can be used to select planting area for pine trees that is suitable for each climate.

\section{ACKNOWLEDGEMENTS}

This study was supported by the Graduate Program Scholarship from The Graduate School, Kasetsart University, Bangkok, Thailand. 


\section{REFERENCES}

Auykim A, Duangsathaporn K, Prasomsin P. 2017. Growth of teak regenerated by coppice and stump planting in Mae Moh Plantation, Lampang province, Thailand. Agric Nat Resour 51 )4(: 273-277. DOI: 10.1016/j.anres.2016.12.009.

Buajan S, Pumijumnong N, Li Q, Liu Y. 2016. Oxygen isotope $\left(\delta^{18} \mathrm{O}\right)$ of teak tree-rings in North-West Thailand. J Trop For Sci 28 (4): 396405 .

Buareal K, Buajan S, Preechamart S, Muangsong C, Pumijumnong N. 2020. A 177 Years extended of teak chronology revealing to the climate variability in Phrae Province Northern of Thailand. App Environ Res 42 (1): 85-100. DOI: 10.35762/AER.2020.42.1.7.

Buckley BM, Barbetti M, Watanasak M, D’Arrigo R, Boonchirdchoo S, Saratunon S. 1995. Dendrochronological investigations in Thailand. IAWA J 16: (4): 393-409. DOI: 10.1163/22941932-90001429.

Buckley BM, Duangsathaporn K, Palakit K, Butler S, Syhapanya V, Xaybouangeun N. 2007. Analyses of growth rings of Pinus merkusi from Lao P.D.R. For Ecol Manag 253: 120-127. DOI: 10.1016/j.foreco.2007.07.018.

Chaudhary V, Bhattacharyya A. 2002. Suitability of Pinus kesiya in Shillong, Meghalaya for tree-ring analyses. Curr Sci 83 (8): 10101015.

Cook ER, Kairiukstis LA. 1990. Methods of Dendrochronology. Kluwer, Dordrecht.

Duangsathaporn K, Palakit K. 2013. Climatic signals derived from the growth variation and cycles of Pinus merkusii in Easternmost Thailand. Thai J For 32 (1): 9-23.

Ferguson CW. 1970. Concepts and Techniques of Dendrochronology. University of California Press, London.

Fritts HC. 1976. Tree Ring and Climate. Academic Press, San Francisco.

Holmes RL. 1983. Computer-assisted quality control in tree-ring dating and measurement. Tree-Ring Bull 43: 69-78.

Khantawan C, Duangsathaporn K, Prasomsin P. 2019. Relationship between carbon content and growth of teak in natural forest and plantation, Lampang Province, Thailand. Agric Nat Resour 53 )3(: 267-273. DOI: 10.34044/j.anres.2019.53.3.08.

Lumyai P, Duangsathporn K. 2017a. Pine growth variation and climate change: Opportunities for dendroclimatology in central Thailand. J Trop For Res 1 (1): 23-35.

Lumyai P, Duangsathaporn K. 2017b. Climate Reconstruction on the Growth of Teak in Umphang Wildlife Sanctuary Thailand. Environ Nat Resour J 16 (1): 21-30. DOI: 10.14456/ennrj.2018.3

Lumyai P, Palakit K, Duangsathaporn K, Wanthongchai K. 2020. A 324 years temperature reconstruction from Pinus latteri Mason at highland in Chiang Mai Province Thailand. Biodiversitas 21 (9): 3938-3945. DOI: 10.13057/biodiv/d210903.

Missanjo E, Matsumura J. 2016. Radial Variation in Tracheid Length and Growth Ring Width of Pinus kesiya Royle ex Gordon in Malawi. Agric For 3 (1): 13-21.

Muangsong C, Cai B, Pumijumnong N, Hu C, Lei G. 2016. Intra-seasonal variability of teak tree-ring cellulose $\delta^{18} \mathrm{O}$ from northwestern Thailand: A potential proxy of Thailand summer monsoon rainfall. Holocene 26 (9): 1397-1405. DOI: 10.1177/0959683616640045.

Muangsong C, Cai B, Pumijumnong N, Lei G, Wang F. 2018. A preliminary study on teak tree ring cellulose $\delta 180$ from Northwestern Thailand: The potential for developing multiproxy records of Thailand summer monsoon variability. Theor Appl Climatol 136 (1): 575-586. DOI: 10.1007/s00704-018-2499-0.

NOAA. 2019. National Centers for Environmental Information, State of the Climate: Global Climate Report for Annual 2018 https://www.ncdc.noaa.gov/sotc/global/201813.

Northern Silvicultural Research Center. 2019. 50 years Pine. Northern Silvicultural Research Center Division of Research Forest Research and Development Office Royal Forest Department, Bangkok.
Palakit K, Duangsathaporn K, Siripatanadilok S, Lumyai P. 2015a. Effects of climate variability on monthly growth of Aglaia odoratissima and Hydnocarpus ilicifolia at the Sakaerat Environmental Research Station (SERS), Northeastern Thailand. Environ Nat Resour J 13 (1): 1-12. DOI: 10.14456/ennrj.2015.7.

Palakit K, Duangsathaporn K, Siripatanadilok S. 2015b. Climatic fluctuations trigger false ring occurrence and radial-growth variation in teak (Tectona grandis L.f.). iForest-Biogeosci For 9 (2): 1-8. DOI: 10.3832/ifor1 100-008.

Palakit K, Siripatanadilok S, Lumyai P, Duangsathaporn K. 2018. Leaf phenology and wood formation of white cedar trees (Melia azedarach L.) and their responses to climate variability. Songklanakarin J Sci Technol 40 (1): 61-68. DOI: 10.14456/sjst-psu.2018.16.

Palakit K, Lumyai P, Duangsathaporn K. 2019. Influence of Climate on the Growth of Teak (Tectona grandis Linn. f.) at a Non-native Distributed Site in Northeastern Thailand. Chiang Mai J Sci 46 (6): 1113-1128.

Preechamart S, Pumijumnong N, Payomrat P, Buajan S. 2018. Variation in climate signals in teak tree-ring chronologies in two different growth areas. Forests 9 (12): 772. DOI: 10.3390/f9120772.

Pumijumnong N, Eckstein D. 2011. Reconstruction of pre-monsoon weather conditions in northwestern Thailand from the tree-ring widths of Pinus merkusii and Pinus kesiya. Trees 25 (1): 125-132. DOI: 10.1007/s00468-010-0528-4.

Pumijumnong N. 2012. Teak tree ring widths: Ecology and climatology research in Northwest Thailand. Sci Technol Dev 31 (2): 165-174.

Pumijumnong N, Palakit K. 2020. Effects of climate variability on the annual and intra-annual ring formation of Pinus merkusii growing in Central Thailand. Environ Nat Resour J 18 (3): 234-248. DOI: 10.32526/ennrj.18.3.2020.22.

Pumijumnong N, Wanyaphet T. 2006. Seasonal cambial activity and tree ring formation of Pinus merkusii and Pinus kesiya in northern Thailand in dependence on climate. For Ecol Manag 226 (1): 279289. DOI: 10.1016/j.foreco.2006.01.040.

Pumijumnong N, Songtrirat P, Buajan S, Preechamart S, Chareonwong U, Muangsong C. 2021. Climate control of cambial dynamics and treering width in two tropical pines in Thailand. Agric For Meteorol 303: 108394. DOI: 10.1016/j.agrformet.2021.108394.

Rakthai S, Fu PL, Fan ZX, Gaire NP, Pumijumnong N, Eiadthong W, Tangmitcharoen S. 2020. Increased drought sensitivity results in a declining tree growth of Pinus latteri in Northeastern Thailand. Forests 11 (3): 361. DOI: 10.3390/f11030361.

Sangram N, Duangsathaporn K, Poolsiri R. 2016. Effect of gases and particulate matter from electricity generation process on the radial growth of teak plantations surrounding Mae Moh power plant, Lampang province. Agric Nat Resour 50 )2(: 114-119. DOI: 10.1016/j.anres.2016.06.001.

Stokes MA, Smiley TL. 1968. An Introduction to Tree-Ring Dating. University of Chicago Press, Chicago, IL

Susatya A, Yansen Y. 2016. Dendrochronology of young Swietenia macrophylla and the variation of its growth response to the past wet climate in Bengkulu, Indonesia. Biodiversitas 17 (2): 446-472. DOI: 10.13057/biodiv/d170210

Voor Tech Consulting. 2008. Measure J2X, http://www.voortech.com/projectj2x/docs/V321/install.htm

Wang X, Zhang M, Ji Y, Li Z, Li M, Zhang Y. 2017. Temperature signals in tree-ring width and divergent growth of Korean pine response to recent climate warming in northeast Asia. Trees 31 (2): 415-427. DOI: $10.1007 / \mathrm{s} 00468-015-1341-\mathrm{x}$.

Wigley TML, Briffa KR, Jones PD. 1984. On the average value of correlated time series, with applications in dendroclimatology and hydrometeorology. J Appl Meteorol Climatol 23 (2): 201-213. DOI: 10.1175/1520-0450(1984)023<0201:OTAVOC>2.0.CO;2.

Yordtong K, Duangsathaporn K Palakit K. 2019. Climatic factors on growth of Pinus latteri Mason in Hill evergreen forest at Phu Kradueng National Park, Loei Province. Thai J For 38 (2): 124-135. 